\title{
Immunogenicity of Plasma-derived Hepatitis B Vaccine:
}

\author{
Relationship to Site of Injection and Obesity
}

A HUNDRED YEARS have elapsed since Louis Pasteur administered the first rabies virus vaccine to young Joseph Meister. Since then, enormous strides have taken place in our ability to immunize against pathogenic viruses and bacteria. More and more sophisticated immunogens have been developed. The crude rabbit spinal cord preparation of Pasteur has given way to well-characterized attenuated virus vaccines and purified, inactivated immunogens.

Active immunization against hepatitis $B$ virus represents the latest chapter in the annals of virus vaccines, and remains a fast-moving field. New vaccines are on the horizon, including one based on the use of hepatitis B virus surface antigen (HBsAg) expressed by and extracted from yeast cells into which the related virus gene sequence had been introduced as recombinant DNA. ${ }^{1}$ For several years, however, a licensed hepatitis B vaccine has been available which is produced from HBsAg-containing human plasma through a complex process involving multiple purification and inactivation steps. $^{2}$

Early clinical trials with this hepatitis B plasma vaccine demonstrated that it was both safe and effective. Intramuscular doses of 20 to $40 \mu \mathrm{g}$ of alumadsorbed antigen elicited serum antibody (anti-HBs) responses that were detectable by solid-phase immunoassay in $85-95 \%$ of healthy homosexual males. ${ }^{3,4}$ Such antibody responses correlated with a high degree of protection against symptomatic infection.

However, when the hepatitis $B$ vaccine was given in recommended doses to hospital workers, under conditions of everyday use, several groups of investigators found that as few as $50-70 \%$ of surveyed individuals had significant antibody responses. ${ }^{5-9}$ These studies may have been flawed. They were retrospective. Also, in some cases postimmunization antibody screening may not have been carried out until up to one year after completion of the recommended three-dose course of vaccine. By this time, antibody levels may have declined somewhat from the maximum levels achieved following immunization. Nonetheless, these studies suggest $\alpha$ poorer response to the vaccine under field conditions than the controlled clinical trials under relatively ideal conditions would have predicted.

These poor results cannot be attributed to impaired vaccine potency or to improper storage (for example, inadvertant freezing of the vaccine prior to its administration). ${ }^{7}$ However, retrospective reviews carried out by the vaccine manutacturer and the Centers for Disease Control suggest that the site of intramuscular injection is an important factor in determining the antibody response to the vaccine. ${ }^{7}$ In the CDC study, among medical centers administering vaccine by injection into the buttocks, postimmunization anti-HBs developed in $82 \%$ of recipients. In contrast, the average vaccine response was $93 \%$ in centers that administered vaccine mainly by deltoid injection.

Why should it matter whether vaccine is administered by buttocks or deltoid injection? The answer is uncertain. However, a hypothesis is suggested by an examination of the early events surrounding the initial immune response to on antigen, and the mechanical factors involved in attempted intramuscular injection in the gluteal region. Usually, in the earliest stages of antibody induction, foreign antigens must be processed by macrophages or similar cells before they are presented to $\mathrm{T}$ and $\mathrm{B}$ lymphocytes. ${ }^{10}$ This processing of the immunogen, which involves phagocytosis and partial degradation, renders it much more immunogenic and results in the release of interleukin I by the involved macrophages. It is the initial step in a complex series of events involving several types of immune effector cells and lymphokines. The end result of this process is the recruitment and selective amplification of specifically reactive lymphocytes and their subsequent differentiation to plasma cells secreting reactive antibody. Thus, for most parenterally administered immunogens to work effectively, immunogenic material must be delivered in a manner that will facilitate phagocytosis and processing by the fixed macrophage or related cells. Alum adjuvants may work in this way; alum-adsorbed antigen is relatively particulate and thus more readily processed by the macrophage.

The site at which immunogens are adminstered could influence subsequent antibody response, for related reasons. Given the thickness of gluteal adipose tissue, most attempts to administer vaccine into muscle by buttocks injection instead deliver the vaccine into adipose tissue. ${ }^{11}$ We would expect that good sites for injection of vaccines would be those (such as muscle) from which injected antigens pass rapidly through the blood to the spleen or through lymphatics to lymph nodes where processing may occur. On the other hand, subcutaneous adipose tissue may be a poor site for vaccine injection because of slow mobilization of antigen. 
This observation may partly explain the failure of hepatitis B plasma vaccine to elicit good antibody responses when administered by gluteal injection.

There is evidence to support this hypothesis. Recently, we and our colleagues found that a high weight-height index (a marker of obesity) correlated with a lack of antibody response following injection of the hepatitis $B$ vaccine into the buttocks. ${ }^{9}$ Only $29.5 \%$ of hospital employees whose weight-height indices were above the sex-adjusted 75th percentile for all Americans had detectable levels of anti-HBs eleven months after completing the vaccine series. On the other hand, antibody was present in $63.3 \%$ of employees whose weightheight indices were below the 75th percentile $(p<$ 0.01 ). These results might be explained by a greater degree of difficulty in achieving true intramuscular delivery of vaccine by buttocks injection in obese individuals.

However, site of injection might not explain all of the problem. A review of the anatomy suggests that the majority of "intramuscular" buttock injections end up in adipose tissue, even in non-obese persons. ${ }^{11}$ So these results could also suggest that mobilization of vaccine from adipose tissue is relatively impaired in obese individuals.

We recently determined that $\alpha$ high weightheight index may also predict a lack of antibody response to hepatitis $B$ vaccine even when it was given by long needles into the deltoid muscle, on injection procedure which should result in vaccine deposition in muscle. ${ }^{12} \bar{A}$ similar finding has been reported by others. ${ }^{13}$ The explanation for these observations remains obscure.

Poor vaccine response rates among some groups receiving vaccine predominantly by deltoid injection ${ }^{7}, 12,13$ hint at other factors, in addition to obesity, that may influence the immunogenicity of this vaccine in everydary usage. Advancing age and male sex may adversely affect response to the vaccine. ${ }^{14}$ Immunocompromised persons, such as hemodialysis patients, may have measurably impaired antibody responses. Certain major histocompatibility complex markers ${ }^{15}$ or impaired $\mathrm{B}$ cell responsiveness to pokeweed mitogen in vitro ${ }^{16}$ might be associated with a poor antibody response following administration of the hepatitis $B$ vaccine. Clearly, many questions remain and there is need for further work in this area.

Intramuscular injection may not be optimal for all non-replicating immunogens. An alternative injection site, such as skin, may sometimes be better. Intradermal injection of hepatitis $B$ virus vaccine and rabies vaccine has been shown to enhance their immunogenicity. ${ }^{17-20}$

In a recently reported, controlled, blinded study, intradermal injection of $2 \mu \mathrm{g}$ (one tenth the normal dose) of hepatitis B plasma vaccine re- sulted in somewhat reduced but probably acceptable antibody levels compared with those achieved with full-dose, intramuscular injection of vaccine. ${ }^{19}$ Similarly, intradermal immunization with 0.1 $\mathrm{ml}$ human diploid cell rabies vaccine prepared by the Merieux Institute (also one tenth the normal, intramuscular dose) results in antibody levels that are acceptable for pre-exposure (but not post-exposure) prophylaxis. ${ }^{20,21}$ It has been suggested that the apparent enhancement of immunogenicity of vaccine given by intradermal injection may be due to efficient uptake and processing of antigen by Langerhans' cells within the epidermis. ${ }^{19}$ Although the phenomenon is not restricted to hepatitis $B$ and rabies vaccines, it has particular, practical implications for immunization against these two diseases.

Successful immunization with reduced doses of vaccine given intradermally may provide a significant cost savings of these two, particularly expensive, vaccines. Moreover, the administration of smaller amounts of vaccine by the intradermal route may permit limited vaccine quantities to be spread among a larger number of people.

A problem with intradermal administration, however, is that particular care must be taken to ensure that vaccine given by this route is not inadvertently administered subcutaneously. This mary take some practice. In any case, intradermal administration of the hepatitis B vaccine is still experimental.

The recent experience with the hepatitis $B$ vaccine should humble all of us. It demonstrates that apparently trivial differences between experimental and field conditions may be of substantial practical importance. Nonetheless, when given by deltoid injection, as currently recommended, ${ }^{2}$ the plasma-derived hepatitis $B$ vaccine is usually very effective in the hospital setting, where hepatitis B infection remains an important occupational hazard. ${ }^{22}$ We should not be dissuaded from its use in persons at high risk for hepatitis B. High-risk workers who have already received three injections of the hepatitis B vaccine by gluteal injection would benefit from testing for anti-HBs. Of those who have remained seronegative, most $(90 \%)$ will develop detectable anti-HBs following an additional two l-ml doses of vaccine given by intramuscular injection into the deltoid muscle (Weber et al., unpublished data). - Stanley M. Lemon, MD, and David J. Weber, MD, MPH, Division of Infectious Diseases, Department of Medicine, University of North Carolina at Chapel Hill, Chapel Hill, North Carolina

\section{REFERENCES}

1. Scolnick EM. McLean AA. West DJ, McAleer WJ, Miller WJ, Buynak EB. Clinical evaluation in healthy adults of a hepatitis $B$ vaccine made by recombinant DNA. JAMA 1984;251:2812-5 
2. Centers for Disease Control, Immunization Practices Advisory Committee. Recommendations for protection against viral hepatitis. MMWR 1985;34:313-35

3. Szmuness W. Stevens CE, Zang EA, Harley EJ, Kellner A. A controlled clinical trial of the efficacy of the hepatitis $B$ vaccine (Heptavax B): a final report. Hepatology 1981;1:377-85

4. Francis DP, Hadier SC, Thompson SE, et al. The prevention of hepatitis $B$ with vaccine. Report of the Centers for Disease Control multi-center efficacy trial among homosexual men. Ann Intern Med 1982;97:3626

5. Rumley RL, Chapman SW. Hepatitis B vaccination of high-risk hospital employees and hemodialysis patients. Abstracts of the 1984 Interscience Conference on Antimicrobial Agents and Chemotherapy, Washington, D.C. October 1984; p 104

6. Schaaff DM, Lender M, Snedeker P. Graham LA. Hepatitis B vaccine in a hospital. Ann Intern Med 1984:101:720-21

7. Centers for Disease Control. Suboptimal response to hepatitis $B$ vaccine given by injection into the buttock. MMWR 1985;34:105-13

8. Pead PJ, Saeed AA, Hewitt WG, Brownfield RN. Low immune responses to hepatitis B vaccine among healthy subjects. Lancet 1985:1:1152

9. Weber DJ. Rutala WA. Samsa GP, Santimaw JE, Lemon SM. Obesity as a predictor of poor antibody response to hepatitis $B$ plasma vaccine. JAMA 1985;254:3187-9

10. Joklik WK. Willett HP. Amos DB (eds). Zinsser microbiology. Norwalk, Cn: Appleton-Century-Crofts, 1984

11. Cockshott WP, Thompson GT, Howlett LJ, Seeley ET. Intramuscular or intralipomatous injections. N Engl J Med 1982:307:356-8

12. Weber DJ, Rutala WA, Samsa GP. Bradshaw SE, Lemon SM. Obesity, not site of immunization, is the key predictor of a poor antibody response to the hepatitis $B$ plasma vaccine. Submitted for publication.

13. Lane TW, Tashjian LS. Ivey F, Gerner H, Via BE. Immunogenicity of hepatitis B vaccination in hospital employees: predicators of seroconversion. Abstracts of the 1985 Interscience Conference on Antimicrobial Agents and Chemotherapy, Minneapolis, October 1985, p 94

14. Jacobson IM, Dienstag JL. Viral hepatitis vaccines. Annu Rev Med 1985:36:241-61

15. Craven DM, Kunches LM, Dienstag JL, et al. Analysis of nonresponsiveness to hepatitis B vaccine in health care workers. Hepatology 1984:4:1077

16. Nowicki MJ, Tong MJ, Bohman RE. Alteration in the immune response of nonresponsers to the hepatitis B vaccine. J Infect Dis 1985:152:12458

17. Miller KD, Gibbs RD, Mulligan MM, Nutman TB, Francis DP. Intradermal hepatitis $B$ vaccine: immunogenicity and side-effects in adults. Lancet $1983: 2: 1454-6$

18. Zoulek G. Lorbeer B. Jitg W. Dienhardt F. Evaluation of a reduced dose of hepatitis B vaccine administered intradermally. J Med Virol $1984 ; 14: 27-32$

19. Redfield RR, Innis BL, Scott RMc, Cannon HG, Bancroft WH. Clinical evaluation of low-dose intradermally administered hepatitis $B$ virus vaccine. JAMA 1985;254:3203-6

20. Centers for Disease Control, Immunization Practices Advisory Committee. Rabies prevention. MMWR 1984;33:393-408

21. Bernard KW, Roberts MA, Summer J. et al. Human diploid cell rabies vaccine: effectiveness of immunization with small intradermal or subcutaneous doses. JAMA 1982;247:1138-42

22. Osterholm MT, Garayalde SM. Clinical viral hepatitis B among Minnesota hospital personnel. JAMA 1985:254:3207-12

\section{The General Internist and Occupational Medicine}

IMAGINE that the scope of general internal medicine suddently doubled, creating $\alpha$ plethora of new research topics, practice opportunities, and challenging cases. Imagine that a demographic shift suddenly meant that large numbers of young adults needed primary care services and gave the problems of geriatrics a new dimension. Imagine that $\alpha$ new and different approach to disease prevention and health promotion opened itself to the internist.

There is a field of medicine that holds out such exciting possibilities. It exists largely in the shadows of medical practice, visible to general internists only in fleeting glimpses yet affecting most of their patients from young adulthood and adolescence to well beyond retirement age. It is a discipline of medicine that overlaps much of general internal medicine in content yet incorporates highly specialized knowledge and approaches to solving problems. It is a mode of medical practice that involves unique and often difficult challenges but contains elements of practice that most internists use every day. It is a distinct medical specialty in form and content but one with so few credentialed specialists that internists now and for years to come will handle more cases in the specialty than the specialists themselves. This branch of medicine is occupational medicine, and it is full of opportunity for general internal medicine..$^{1.2}$

This is so because occupational medicine, like internal medicine, is concerned with adults, both while they are of working age and into their retirement. Most adults spend a third of their waking hours at work, and social psychologists have shown that work (or the lack of it) is a critical element in a person's life, identity, and self-esteem. ${ }^{3,4}$ This is an aspect of the patient's life that the general internist can ill afford to ignore, because work plays an important role in health and the patient's health has important implications for work.

The organized specialty of occupational medicine is now at a crossroads - actually a crisis because the supply of trained and interested physicians falls far short of demand. ${ }^{5}$ A great expansion in the demand for occupational health services has led to a much greater involvement of other medical specialists and of primary care practitioners, including internists.

After months of deliberation, the American College of Physicians in 1984 adopted a position paper on the internist and occupational medicine. ${ }^{6}$ This important paper, summarized in the November 1984 issue of the ACP Observer, emphasizes two main points: Internists should be responsive to the occupational health needs of their patients and should be prepared to identify occupationallyassociated disorders and health concerns. Physicians are also judged to have a responsibility to improve health standards by supporting and participating where possible in the prevention of occupational disorders. The internists' role in 